\title{
ESTUDO DO ARRASTO DE PARTÍCULAS DE POEIRA DEPOSITADAS EM MÓDULOS FOTOVOLTAICAS POR MEIO DE JATOS DE AR: UMA ANÁLISE CFD
}

Pedro Freire de Carvalho Paes Cardoso 11; Turan Dias Oliveira 22; Paulo Roberto Freitas Neves 32; Juliana de Oliveira Cordeiro 4²; Luzia Aparecida Tofaneli 5²; Alex Álisson Bandeira Santos $6^{2}$

$1 \quad$ Centro Universitário $\quad$ SENAI CIMATEC;
pedropcardoso06@gmail.com
${ }^{2}$ Centro Universitário SENAI CIMATEC; Salvador/Bahia

Resumo: O uso de sistemas energia solar fotovoltaica cresce consideravelmente em todo o mundo. Pesquisas mostram que os módulos fotovoltaicos (FV) são consideravelmente afetados pela existência de poeira e sua deposição nas superfícies dos módulos, levando à redução da eficiência do sistema. Este trabalho tem como objetivo desenvolver um estudo, utilizando a Dinâmica dos Fluidos Computacional (CFD), sobre o uso de jatos de ar para promover o arrasto das partículas de poeira, removendo-as da superfície de módulos. Um modelo foi desenvolvido utilizando uma análise Euleriana, baseada em parâmetros físicos, a fim de descobrir a velocidade do ar para promover o arraste da poeira. Através do uso do software ANSYS CFX 17.1, foi possível realizar a montagem e simulação do modelo e adquirir dados importantes.

Palavras-Chave: fotovoltaico; poeira; CFD; ar.

\section{STUDY OF DUST PARTICLES DRAGING IN PHOTOVOLTAIC MODULES USING CONTINUOUS AIR JETS: A CFD ANALYSIS}

\begin{abstract}
The use of photovoltaic solar energy systems grows considerably throughout the world. Researches show that photovoltaic (PV) modules are considerably affected by the existence of dust and its deposition on the surfaces of the modules, leading to the reduction of system efficiency. This work aims to develop a study, using Computational Fluid Dynamics (CFD), on the use of air jets to promote the drag of dust particles, removing them from the surface. The model was developed using an Eulerian analysis, based on physical parameters, in order to discover the velocity of the air to promote the drag of the dust. Through the use of the ANSYS CFX 17.1 software, it was possible to carry out the assembly and simulation of the model and acquire important.
\end{abstract}

Keywords: photovoltaic; dust; CFD; air. 


\section{INTRODUCTION}

The use of renewable energy sources grows significantly throughout the world. Photovoltaic solar energy systems have been significantly involved since the increase, due to the high availability of energy resources to be used to generate electricity, as well as the ease of installation, low maintenance costs compared to other types of generators and not to significant damage to the planet. Much research has been done on photovoltaic modules to increase their efficiency and reduce operating losses due to environmental effects.

According to the review developed by Said, A.M.S. et al. [1], the main environmental factors that negatively and positively interfere with the performance of photovoltaic modules are: ambient temperature, wind, humidity, pollution and dust deposition. These factors influence the system both separately and acting together. As for the presence of the dust Said, A.M.S. et al. [1] exposes that it can interfere in the performance of the photovoltaic modules both by the dust present in the atmospheric air, whose dimension is greater than the wavelength of the solar rays and there is the occurrence of diffraction of a portion of the rays, but also by the presence of particles accumulated on the surfaces of the modules that prevent parts of the solar rays from entering the interior.

Several researches have been carried out to study how environmental effects interfere with the variation of the amount of dust deposition in PVs and to develop functions to quantify the deposition related to other variables. Researches such as those from Saidan, M. et al. [2] and Gholami, A. et al. [3] have developed experiments to relate the decay of PV yields with the time of exposure to the environment and the deposited dust density. In a similar study Beattie, N.S. et al. [4] also developed a research whose result enabled the mathematical modeling of dust deposition and the comparison with experimental data.

In the studies of Lin Lu, H.J. et al. [5] and Nahar, N. M. et al. [6] it was possible to conclude that the efficiency decrease of the modules by dust particles is also related to the type of material used in them. It was observed that in modules with different materials and the same density of particles had different yield losses.

Taking into account the finding by Said, A.M.S. et al. [1] that many researches were developed to understand and measure the environmental factors that affect the PVs, however, there is still little research that is directed at providing solutions to minimize the environmental factors that result in negative effects. From this point the present research has the objective to develop a study to solve the loss of income generated by the accumulation of dust particles on the surface of PVs, using air jets to promote the drag of the same ones.

The study of the case will be developed using CFD analysis, where it is expected to develop a simulation model in which the air velocity data necessary to remove particles from the surface in different situations and environments can be acquired, changing in each case their parameters and getting the results for them. Other analyzes in CFD for studies in photovoltaic modules have already been developed by 
Dórea, T.L.L. et al. [7], in which simulations were developed to verify the effects of the use of fairings in acceleration of air masses with the intention to promote the increase of the cooling of the PVs and thus reducing your yield loss by increasing the temperature.

In order to carry out the desired simulation, it is necessary to characterize the local dust in the city of Salvador, so that the data are imputed in the analysis and the model can be validated from experiments. The characterization of local dust is still under development. Therefore, while there is no such data, the simulation was developed from the dust characterized in the works of Said, S.A.M. et al. [8], Fukushima, S. et al. [9] and Adinoyi, J.M. et al. [10] from the particle size and number exposed in the samples.

The final objective of the study is to develop a fairing or device that enables the cleaning of photovoltaic modules using air jets. In this way, it was hoped that it would be possible to replace the use of water that is widely used for the cleaning of hundreds or even thousands of modules in solar plants.

\section{METHODOLOGY}

\subsection{Mathematical modeling}

To describe the behavior of the fluid a mathematical modeling becomes necessary. The dynamic fluid equations describing fluid behavior are the mass conservation and momentum equations (Navier-Stokes equations) shown below:

$$
\begin{aligned}
& \frac{\partial \rho}{\partial t}+\operatorname{div}(\rho \vec{u})=0 \\
& \frac{\partial(\rho u)}{\partial t}+\operatorname{div}(\rho u \vec{u})=-\frac{\partial p}{\partial x}+\operatorname{div}(\mu \quad \operatorname{grad} \quad u)+S_{M x} \\
& \frac{\partial(\rho v)}{\partial t}+\operatorname{div}(\rho v \vec{u})=-\frac{\partial p}{\partial y}+\operatorname{div}\left(\begin{array}{lll}
\mu & \operatorname{grad} & v
\end{array}\right)+S_{M y} \\
& \frac{\partial(\rho w)}{\partial t}+\operatorname{div}(\rho w \vec{u})=-\frac{\partial p}{\partial z}+\operatorname{div}(\mu \quad \operatorname{grad} \quad w)+S_{M z}
\end{aligned}
$$

In these equations, $\mathrm{p}$ is pressure; $\mathrm{t}$ is time; $\mathrm{x}, \mathrm{y}$ and $\mathrm{z}$ represent the three Cartesian directions; $\mathrm{u}, \mathrm{v}$ and $\mathrm{w}$ are the velocities in the directions $\mathrm{x}, \mathrm{y}$ and $\mathrm{z}$; is the three-dimensional velocity vector; $\mu$ is the viscosity of the fluid; $\rho$ is the specific mass; SMx, SMy e SMz are the momentary terms in the directions described. 
The flow of the fluid carrying particles has a turbulent behavior, therefore a turbulence model is necessary to correctly describe the behavior of the flow. For the choice of the model, it was considered that the region of interest to be analyzed, the region superior to a surface of a $\mathrm{PV}$, is a boundary layer region and therefore needs a model that describes well the behavior of the fluid in this region. Therefore, the model of turbulence adopted was the model SST k- $\omega$, which in turn requires the resolution of the equations of transport of turbulent kinetic energy " $k$ " and a turbulent frequency " $\omega "$. Both equations are shown below:

$$
\begin{gathered}
\frac{\partial(\rho k)}{\partial t}+\operatorname{div}(\rho k \vec{u})=\operatorname{div}(\Gamma \operatorname{grad} k)+S_{k} \\
\frac{\partial(\rho \omega)}{\partial t}+\operatorname{div}(\rho \omega \vec{u})=\operatorname{div}(\Gamma \operatorname{grad} \omega)+S_{\omega}
\end{gathered}
$$

In these equations, Sk and $\mathrm{S} \omega$ are the source terms of $\mathrm{k}$ and $\omega$ respectively and may have their equations found in the literature.

To solve the equations described above, the Finite Volumes method was adopted using the ANSYS CFX 17.1 software.

\subsection{Geometry and mesh}

The geometry for the simulation was constructed by imagining a fluid domain around a surface of a photovoltaic module where a mass of air can flow at a certain speed. To reduce the simulation time a geometry with much smaller thickness than the other dimensions was used to approximate the model of a $2 \mathrm{D}$ condition. The dimensions of the modules were based on the photovoltaic solar module model HP30P, with dimensions $(\mathrm{LxW} x \mathrm{H})$ of $610 \times 350 \times 25 \mathrm{~mm}$. The Fig. 1 below shows all relevant dimensions of the geometry used.

Figure 1. Geometry used in the simulations and its dimensions

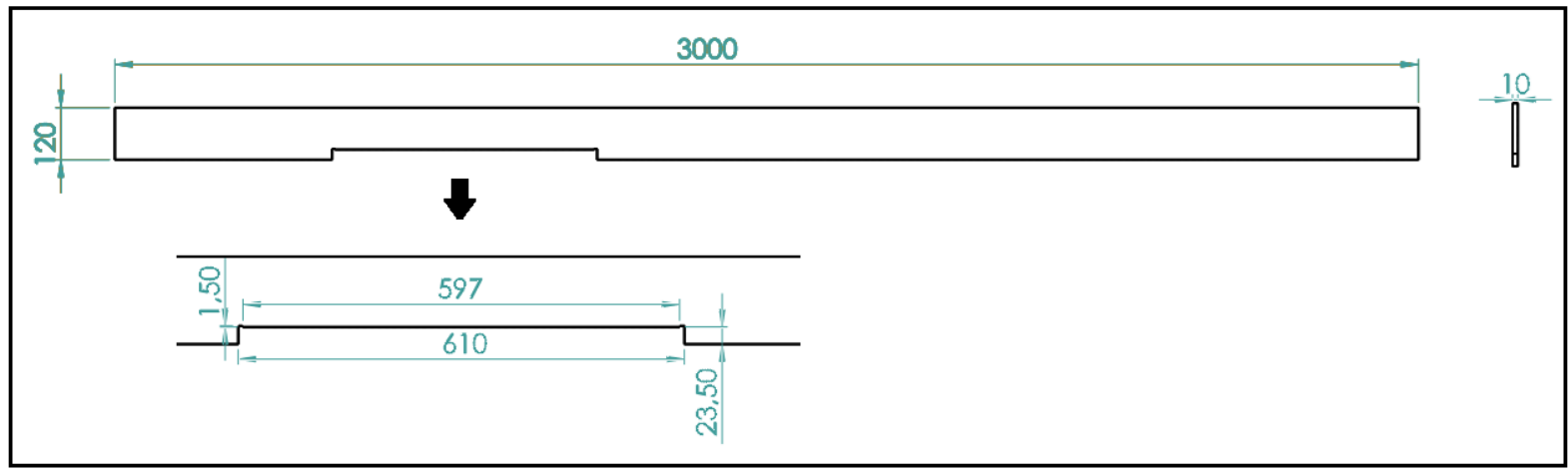


The mesh was constructed using elements with a dimension of $1 \mathrm{~mm}$, with 680318 nodes and 337039 elements. Fig. 2 shows the mesh developed for the geometry.

Figure 2. Mesh

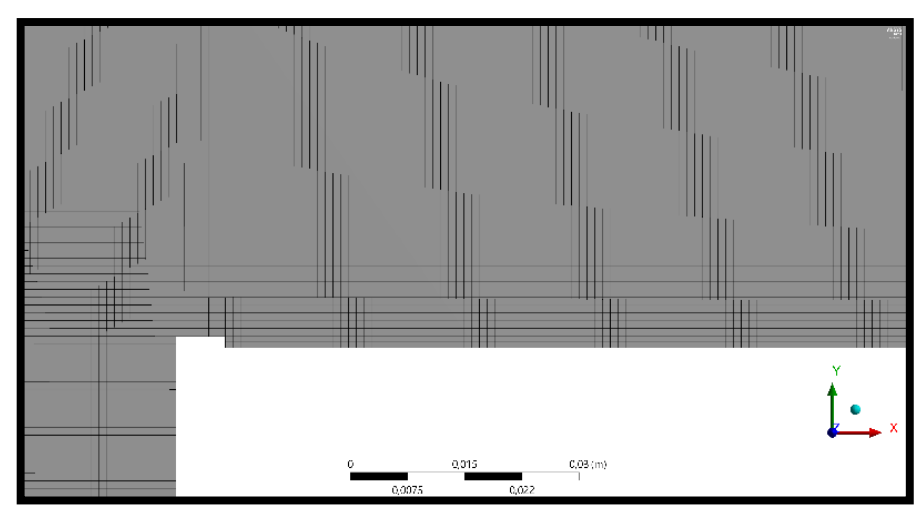

\subsubsection{Boundary Conditions}

To enable the visualization of the behavior of the set of particles, the analysis performed will be the Eulerian and transient with steps of $0.2 \mathrm{~s}$, totaling $6 \mathrm{~s}$. A layer of $1 \mathrm{~mm}$ of dust particles was placed in the region above the surface of the modules, with a percentage of $70 \%$ (the remaining $30 \%$ are occupied by air present between the particles), the remainder of the domain consists of stagnant air at pressure environment, $101.3 \mathrm{kPa}$.

The surface of the right side was called the entrance, where there was an air inlet of $1 \mathrm{~m} / \mathrm{s}$, the two lateral surfaces were determined as a condition of symmetry, the upper and lower surfaces were placed as walls without sliding and the left lateral end was called output, the opening condition was set. The Fig. 3 shows the boundary conditions in the model.

Figure 3. Boundary Conditions

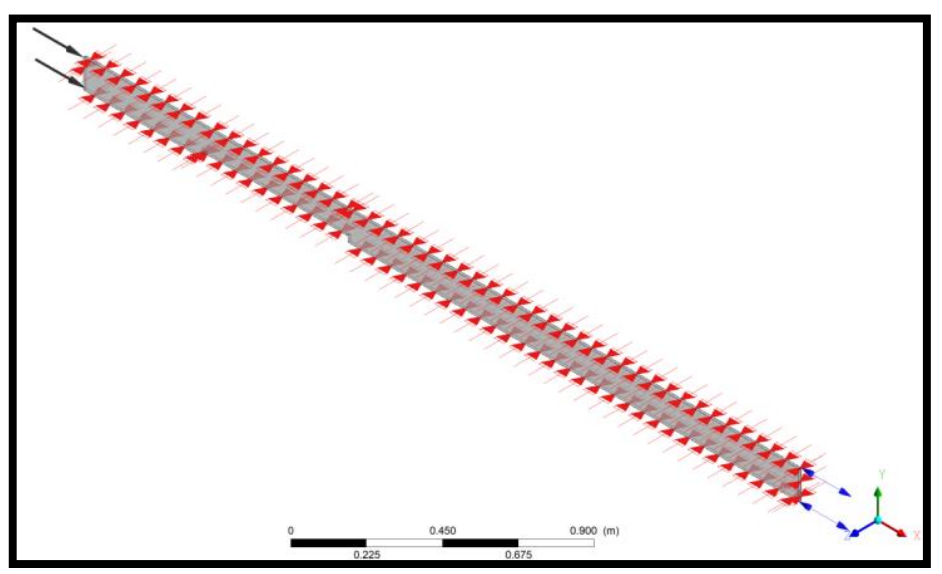




\section{RESULTS}

After the simulation was carried out, it was possible to verify the loading of the dust particles due to the action of the air flow and this model could serve as a basis for the next simulations with the higher level of detail. The Fig. 4 shows the results of simulation.

Figure 4. Fraction of dust volume as a time function

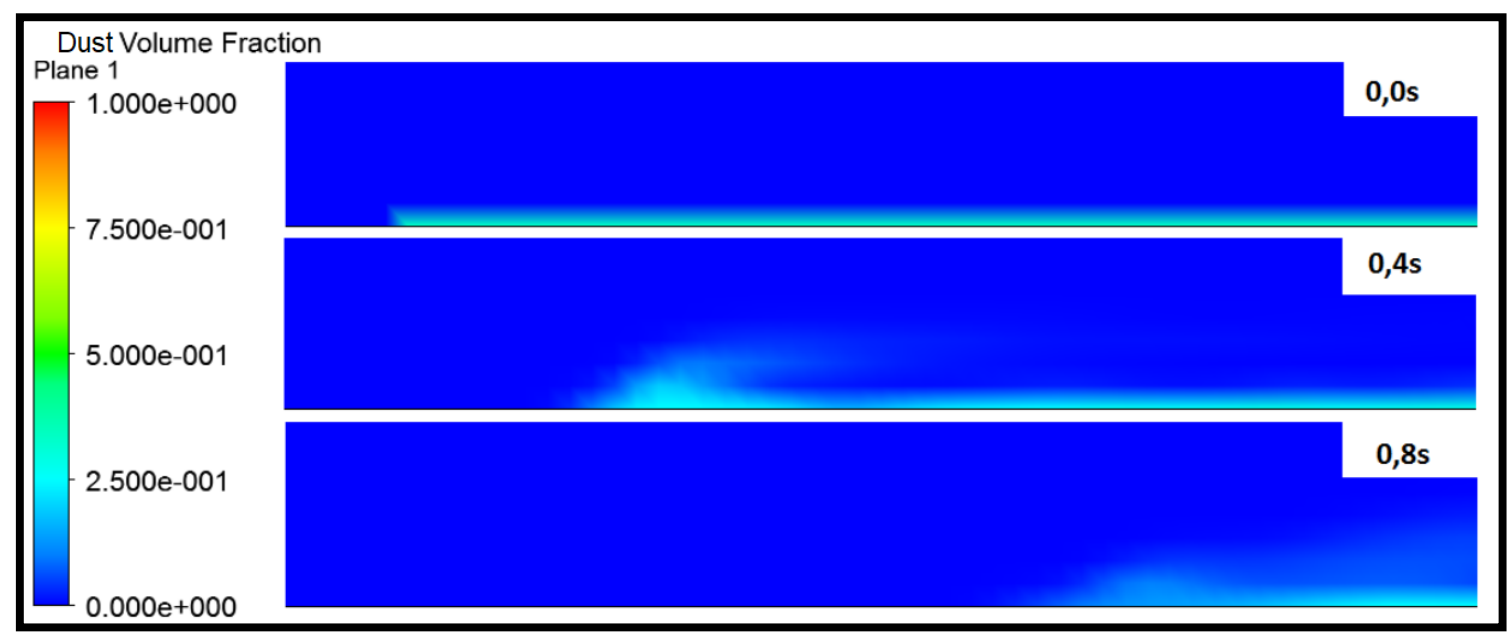

\section{CONCLUSION}

It has not yet been possible to reach significant conclusions regarding the use of air jets for the cleaning of modules since the final model is still under development. However, production has shown to be significant and the simulations are showing consistent results. For the complete conclusion of the work, the lack of an adhesion force ratio of the dust particles between them and in relation to the surface of the modules, besides the characterization of the local dust, is lacking. Both stages are in development and it is expected that the final modeling can be validated through experiments.

\section{Acknowledgements}

My thanks to SENAI CIMATEC University Center and the Energy Lab professors and professionals for the opportunity given to me to develop the present work and to (FAPESB) for their support and encouragement of research. 


\section{REFERENCES}

1SAID, A.M.S. et al. The effect of environmental factors and dust accumulation on photovoltaic modules and dust-accumulation mitigation strategies. ELSEVIER, Renewable and Sustainable Energy Reviews, 82, pg. 743-760, 2018.

${ }^{2}$ SAIDAN, M. et al. Experimental study on the effect of dust deposition on solar photovoltaic panels in desert environment. ELSEVIER, Renewable Energy, 92, pg. 499-505, 2016.

${ }^{3}$ GHOLAMI, A. et al. Experimental study of factors affecting dust accumulation and their effects on the transmission coefficient of glass for solar applications. ELSEVIER, Renewable Energy, 112, pg. 466-473, 2017.

${ }^{4}$ BEATTIE, N.S. et al. Understanding the effects of sand and dust accumulation on photovoltaic modules. ELSEVIER, Renewable Energy, 48, pg. 448-452, 2012.

${ }^{5}$ LIN LU, H.J. et al.. Experimental investigation of the impact of airborne dust deposition on the performance of solar photovoltaic (PV) modules. ELSEVIER, Atmospheric Environment, 45, pg. 4299-4304, 2011.

${ }^{6} \mathrm{NAHAR}, \mathrm{N}$. M. et al. Effect of dust on transmittance of glazing materials for solar collectors under arid zone conditions of India. ELSEVIER, Solar e Wind Technology, 7, pg. 237-243, 1990.

${ }^{7}$ DÓRIA, T.L.L. et al. ESTUDO DA INFLUÊNCIA DE CARENAGENS NA EFICIÊNCIA DE PAINÉIS FOTOVOLTAICOS - UMA ABORDAGEM ENERGÉTICA E FLUIDODINÂMICA. CIBEM, 2017.

${ }^{8}$ SAID, A.M.S. et al. Fundamental studies on dust fouling effects on PV module performance. ELSEVIER, Solar Energy, 107, pg. 328-337, 2014.

${ }^{9}$ FUKUSHIMA, S. et al. Comparison in size and elemental composition of dust particles deposited to the surface and suspended in the air on the southwest Japan coast. ELSEVIER, Atmospheric Environment, 118, pg. 157-163, 2015.

${ }^{10} \mathrm{ADINOYI}$, J.M. et al. Effect of dust accumulation on the power outputs of solar photovoltaic modules. ELSEVIER, Renewable Energy, 60, pg. 633-636, 2013. 